Rocking

the

boat

\section{Robert Ubell}

\section{Naked Emperors: Essays of}

a Taboo-Stalker.

By Garrett Hardin.

William Kaufmann/W.H. Freeman:

1983. Pp.280. Hbk \$15, £12.95;

pbk \$8,95, £6.95.

THIS is a work of great mischief. Wrapped in the cloak of science, it cannot totally conceal its naked racism and chauvinism. If Garrett Hardin did not have a large following among ecologists and population and resource management experts, one would be tempted to dismiss his vulgar exploitation of biology. But just as Herman Kahn's facile talk of nuclear war games made a holocaust appear palatable at tea-time, so Hardin's glib prescriptions for salvation permit us to accept starvation, sterilization and civilized savagery.

Hardin first came to prominence with the publication of his undergraduate biology textbook in the late 1940s. In it, he claimed that because people with the most education have low reproduction rates and those with low IQ scores breed profligately, we should expect a continuous downward trend in average intelligence. To avoid the consequences of this effect, he adopted the tenets of the eugenics movement and called for "measures aimed at discouraging the breeding of less-desired types of humans", mainly by sterilization. Hardin is much tougher than his Social Darwinist predecessor, Herbert Spencer, who merely said, "If the poor died of their own foolishness, the species would improve".

In the 1970s Hardin went on to promulgate his famous "lifeboat ethics". A seductive metaphor, it drew a picture of two lifeboats bobbing on the sea. In one were the rich nations, comfortably basking in wealth and culture. In the other, overcrowded, boat were the poor people of the world - continually falling into the water, flailing about, clamouring to be hoisted aboard the privileged vessel. According to Hardin, the wealthy nations are not merely fortunate: they are guardians of "civilization and dignity". So their task is to keep their boat afloat, preventing it from sinking under the weight of the poor. If the rich do not withhold resources from those who need 'help' to survive, the poor will inevitably over-breed, making a bad situation worse. We will all go under, unless we

- The second edition of Geothermal Energy by H. Christopher H. Armstead, published by E \& F.N. Spon, is now available. The first edition was reviewed in Nature 284, 380; 1980. "let 'em starve" as the National Observer once characterized Hardin's scheme.

Hardin offers a simple analysis: food and energy are scarce; overpopulation stretches the limits; the wealthy few must protect their preserve from the breeding poor. But he neglects to inform us that the United States alone, with only $5 \%$ of the world's population, consumes about $40 \%$ of the world's aluminium, nearly $30 \%$ of its iron, more than $60 \%$ of its natural gas, and a third of its petroleum. It seems rather perverse to condemn the poor for profligacy.

Moreover, it would seem that the underdeveloped nations can do without the 'help' they receive from industrialized parts of the world. In 1981, foreign investment in the Third World amounted to

\section{Dialogue in motion}

\section{K. E. Machin}

Animal Mechanics, 2nd Edn.

By R. McNeill Alexander.

Blackwell Scientific: 1983. Pp.301. f15, \$25.95.

ATHOUGH mechanics is undoubtedly part of physics, the relatively new and fashionable subject of biophysics has never laid claim to animal mechanics, which has therefore been able to lie low in zoology departments and in the pages of the Journal of Experimental Biology. Long may it remain so: animal mechanics flourishes best where the importance and interrelation of form and function are understood, with natural selection providing the ultimate incentive for getting the design right. Actually animal mechanics is not so much a subject as an approach looking at the animal kingdom through a physicist's eyes. Even an approach needs a good textbook; this is it.

Modern biologists, we all agree, must be numerate; we are delighted when a biology undergraduate arrives armed with " $A$ " levels in physics and mathematics. Yet all too of ten we fail to build on this good foundation; the undergraduate may even revert to the wild-type and develop a phobia for things quantitative. We need to find a better way to teach biologists to think quantitatively.

In the first edition of this book (published in 1968) Alexander did just this, inventing a method of feeding mechanics to zoologists in a very palatable form:

Each chapter consists of alternate sections on mechanics and zoology: a section explaining a group of mechanical principles is followed by one or more sections describing zoological investigations in which those principles have been used.

Had he been writing four hundred years ago, Alexander would no doubt have started his title with "Dialogue . . "'. The
$\$ 62.6$ billion; but profits repatriated to investor countries came to $\$ 139.7$ billion.

In Naked Emperors, a collection of recent articles written for professional journals and for such popular American magazines and newspapers as The New Republic and the Los Angeles Times, Hardin continues to cling to his early themes. Because he holds a professorship in human ecology at the University of California at Santa Barbara, is frequently seen on television, and speaks from the pulpit of scholarly periodicals, Hardin is taken seriously. It was Ortega y Gasset who once said, "Contemporary science. . . can put blockheads to good use".

Robert Ubell, until recently the American publisher of Nature, is head of a science publishing house in New York.

mechanics might have been put into the mouth of a middle-aged natural philosopher - a rather formal, didactic man; his companion - a young, quickwitted naturalist - avidly seizes each new chunk of physics and applies it with enthusiasm and delight to his zoological observations. Nowadays, I suppose, the physicist and zoologist would be carried on the left and right channels of a stereo radio programme. But whatever the medium, the pedagogic technique works: before the zoologist can get too bored with equations, he is whisked back into his own territory to see the physics actually working on animals. One learns a subject by using it. In this way, Alexander introduces statics and dynamics, mechanics of machines, elasticity and strength of materials, viscosity and surface tension, hydrostatics and fluid dynamics, vibrations and sound. These topics, potentially dull as an engineering course, come alive through the zoological examples.

Those who have for years been using the first edition of Animal Mechanics will ask: how different is this new edition? The approach, the chapter headings and much of the material will be familiar. But the subject has not stood still: several new topics have joined the "mechanics" sections, and many new zoological examples have been introduced. There are many worthwhile changes of detail: the layout, typography and physical make-up of the book have improved notably; SI units are used throughout (editors of biological journals, please copy); the occasional infelicity has been tidied up; the index is vastly improved.

In his preface, Alexander says: "I was sorry to realize when I had completed this edition, that little mention of the work of Sir James Gray remains in it ". He need nol worry: the whole book is imbued with Gray's spirit.

K.E. Machin is a Lecturer in the Department of Zoology, University of Cambridge, and a Fellow of Queens' College. 